\title{
Nonylphenol promotes the proliferation of colorectal cancer COLO205 cells by upregulating the expression of protein kinase $\mathrm{C} \zeta$
}

\author{
XUEFENG YANG ${ }^{1}$, HANDONG HUANG $^{1}$, MAIJIAN WANG $^{1}$, XINGBIN ZHENG $^{1}$, MING XIE $^{1}$ and JIE XU $^{2}$ \\ ${ }^{1}$ Department of Gastrointestinal Surgery, Affiliated Hospital of Zunyi Medical College, Zunyi, Guizhou 563000; \\ ${ }^{2}$ School of Public Health, Zunyi Medical College, Zunyi, Guizhou 563003, P.R. China
}

Received November 11, 2017; Accepted September 28, 2018

DOI: $10.3892 / \mathrm{ol} .2018 .9846$

\begin{abstract}
Previous studies have indicated the potential role of estrogen in the development and prognosis of colorectal cancer (CRC). Nonylpheno (NP) is an endocrine-disrupting chemical, which may influence the development of estrogen-dependent types of cancer. However, the molecular mechanism of NP in the development of CRCs remains unclear. In the present study, various concentrations of NP were used to treat COLO205 CRC cells, and the expression of protein kinase $\mathrm{C} \zeta(\mathrm{PKC} \zeta)$ was knocked down using $\mathrm{PKC} \xi$ small interfering RNA. The effects of NP in various concentrations on the cell cycle and apoptosis of COLO205 cells were examined, and the change in the expression level of PKC $\zeta$ was analyzed. The results indicated that NP may significantly induce proliferation of COLO205 CRC cells, and significantly reduce cell apoptosis. However, suppression of PKC $\zeta$ expression may inhibit proliferation, while NP could reduce this inhibition. The results of a western blot analysis indicated that the expression level of cyclin D1 and E were significantly increased following NP treatment, and the expression of p27 was significantly decreased. The phosphorylation of PKC $\zeta$ and extracellular-signal-regulated kinase (ERK)1/2 was significantly increased following NP treatment in a dose-dependent manner. Overall, NP induced human CRC COLO205 cell proliferation and inhibited the apoptotic rate of COLO205 cells by increasing the activity of PKC $\zeta$ and ERK1/2.
\end{abstract}

\section{Introduction}

Colorectal cancer (CRC) was the third most common carcinoma of the human digestive system worldwide in 2014 (1). Influenced by genetic, environment and life style factors, the risk of CRC

Correspondence to: Dr Jie Xu, School of Public Health, Zunyi Medical College, 6 Xuefuxi Road, Zunyi, Guizhou 563003, P.R. China

E-mail: xujie360@sina.com

Key words: nonylphenol, colorectal cancer, protein kinase C $\zeta$, proliferation has increased annually, becoming one of the most common types of cancer with a high mortality rate reported in China (2014) (1). The current treatments of CRC are primarily surgery and chemotherapy (2). A previous study indicated that estrogen serves a potential role in the development and prognosis of CRC (3).

With the development of modern industry, numerous endocrine-disrupting chemicals (EDCs), including nonylphenol(NP) and bisphenol A, have been identified in the environment (4-7). EDCs may have an estrogen-associated or androgen-associated effect by binding to hormone receptors and promoting the development of hormone-dependent tumors (8). NP is an EDC, which could influence the development of estrogen-dependent cancer types, including breast and prostate cancer $(9,10)$. Our previous study indicated that NP could activate extracellular-signalregulated kinase (ERK)1/2 to induce the proliferation of CRCs cells (11). However, the underlying molecular mechanism of NP on the development of CRCs remains unclear.

Protein kinase C (PKC), which exists in various cells and tissues, is a type of multifunctional serine and threonine kinase. This protein could mediate the proliferation and differentiation of cells, and has been reported to be involved in the regulation of the cell cycle and apoptosis, promoting the development and metastasis of tumors (12). PKC $\zeta$ is a member of the PKC family, which influences proliferation and transfer of various types of cancer cells (13-15). Inhibiting the expression of $\mathrm{PKC} \zeta$ may reduce the invasion ability of CRC, breast cancer and glioma (16). To the best of our knowledge, no evidence exists on whether NP could mediate the development of CRC by regulating the expression of $\mathrm{PKC} \xi$.

To further examine the effect of NP on the proliferation of $\mathrm{CRC}$ cells and the expression and activity of $\mathrm{PKC} \zeta$, different concentrations of NP were used to treat the COLO205 CRC cells, and to knock down the expression of PKC $\zeta$ by $P K C \zeta$ small interfering (si)RNA. The in vitro effects of NP were further examined with different concentrations of NP on the cell cycle and apoptosis of COLO205 cells, and the altered expression of $\mathrm{PKC} \zeta$ was analyzed.

\section{Materials and methods}

Cell culture and treatment. Human CRC COLO205 cells were obtained from the Chinese Academy of Sciences Institute 
of Cell Resource Center (Shanghai, China). The cells were cultured in RPMI-1640 (GE Healthcare Life Sciences, Little Chalfont, UK) supplemented with $10 \%$ fetal bovine serum (FBS; Procell Life Science \& Technology Co., Ltd., Wuhan, China), $100 \mathrm{IU} / \mathrm{ml}$ penicillin and $100 \mathrm{mg} / \mathrm{ml}$ streptomycin at $37^{\circ} \mathrm{C}$ in an atmosphere containing $5 \% \mathrm{CO}_{2}$. NP with analytical standard purities was purchased from Shanghai Aladdin Biochemical Technology Co., Ltd. (Shanghai, China), and was dissolved in absolute ethyl alcohol to $50 \mathrm{mM}$.

siRNA design and cell transfection. The siRNA oligo was synthesized by Sangon Biotech Co., Ltd., (Shanghai, China). Sequences were as follows: si-PKC' 6, 5'-GGAGGACCTTA AGCCAGTT-3' and siRNA negative control (NC) 5'-AGA CTGTGAATCTAGATCAAG-3'.

For transfection, COLO205 cells were cultured for $12 \mathrm{~h}$ in RPMI-1640 medium supplemented with 10\% FBS, $100 \mathrm{U} / \mathrm{ml}$ penicillin and $0.1 \mathrm{mg} / \mathrm{ml}$ streptomycin, and the fragment of siRNA $(50 \mathrm{nM})$ was transfected using Lipofectamine ${ }^{\circledR} 2000$ (Invitrogen; Thermo Fisher Scientific, Inc., Waltham, MA, USA), according to the manufacturer's protocol. After $72 \mathrm{~h}$ of transfection, cells were washed by PBS and then lysed with 1X radioimmunoprecipitation (RIPA) buffer (Beyotime Institute of Biotechnology, Haimen, China) supplemented with $0.2 \mathrm{mM}$ phenylmethylsulphonyl fluoride protease inhibitor (cat. no. 36978; Thermo Fisher Scientific, Inc.) for $30 \mathrm{~min}$ on ice for western blot analysis.

MTT analysis. Cell viability was detected using the CellTiter $96^{\circledR}$ Non-Radioactive Cell Proliferation assay (MTT; cat. no. G4000; Promega Corporation, Madison, WI, USA). COLO205 cells $\left(1 \times 10^{4}\right.$ cells $\left./ \mathrm{ml}\right)$ were seeded in 96 -well plates for $24 \mathrm{~h}$ prior to treatment, with normal saline and cell culture mediums serving as the control, and three wells were prepared for each of the following groups: $0 ; 1 \times 10^{-6} ; 1 \times 10^{-7}$ and $1 \times 10^{-8} \mathrm{~mol} / 1 \mathrm{NP}$ alone $(17,18) ; 1 \times 10^{-6} \mathrm{~mol} / \mathrm{l} \mathrm{NP}$ with si-PKC $\zeta$; and $1 \times 10^{-6} \mathrm{~mol} / \mathrm{l}$ $\mathrm{NP}$ with NC. Following treatment for $0,24,48$ and $72 \mathrm{~h}$, a total of $15 \mu \mathrm{l}$ provided dye solution was added to each well, and the 96-well plate was incubated at $37^{\circ} \mathrm{C}$ for $4 \mathrm{~h}$, subsequent to adding $100 \mu 1$ Solubilization/Stop Solution from the kit. Viability was recorded at a wavelength of $570 \mathrm{~nm}$ on a microplate reader (Multiskan; Thermo Fisher Scientific, Inc.). The assay was repeated in triplicate.

Flow cytometry analysis of cell cycle and apoptosis. The effect of NP and si-PKC $\zeta$ on cell cycle progression was determined by flow cytometry. After $24 \mathrm{~h}$ of treatment, the cells were digested and fixed with $70 \%$ ethanol for $24 \mathrm{~h}$ at $4^{\circ} \mathrm{C}$. Following fixation, cells were stained with $50 \mu \mathrm{g} / \mathrm{ml}$ propidium iodide (PI) solution and $100 \mu \mathrm{g} / \mathrm{ml}$ RNase A in PBS for $30 \mathrm{~min}$ in the dark on ice and then subjected to cell cycle analysis. The apoptotic rate was measured using Annexin V/PI double staining (Annexin V-FITC Apoptosis Detection kit; cat. no. C1062; Beyotime Institute of Biotechnology). A total of $300 \mu \mathrm{l}$ binding buffer was used for cell resuspension $1 \times 10^{6}$, and $5 \mu \mathrm{l}$ Annexin V-fluorescein isothiocyanate was added to the cell suspension for $10 \mathrm{~min}$ in the dark at room temperature. A total of $5 \mu \mathrm{l}$ PI was subsequently added to the cell suspension for $5 \mathrm{~min}$ in the dark on ice. The samples were analyzed with a FACSCalibur flow cytometer and the FACSCalibur system (both BD Biosciences, Franklin Lakes, NJ, USA).
Western blot analysis. Total protein was extracted from COLO205 cells following treatment using RIPA buffer, and the concentrations were determined by bicinchoninic acid (Thermo Fisher Scientific, Inc.). A total of $40 \mu \mathrm{g}$ total protein was separated by SDS-PAGE (10\% spacer gel and 5\% separation gel). Proteins were transferred to a polyvinylidene difluoride membrane (EMD Millipore, Billerica, MA USA), and membranes were subsequently blocked with $5 \%$ skim milk powder (BD Biosciences) for $60 \mathrm{~min}$ at room temperature. The membranes were subsequently incubated with the following primary antibodies: Cyclin D1 (dilution, 1:800; cat. no. ab134175); cyclin E (dilution, 1:800; cat. no. ab33911), B-cell lymphoma 2 (Bcl-2) associated agonist of cell death (Bad; dilution, 1:500; cat. no. ab62465), Bcl-2 (dilution, 1:1,000; cat. no. ab32124), cyclin-dependent kinase inhibitor (p27; dilution 1:1,000; cat. no. ab32034), PKC $\zeta$ (dilution 1:1,500; cat. no. ab59364), phosphorylated (p)-PKC $\zeta$ (dilution 1:1,500; cat. no. ab62372) (all from Abcam, Cambridge, MA, USA), ERK1/2 (dilution 1:1,000; cat. no. 4695; Cell Signaling Technology, Inc., Danvers, MA, USA), p-ERK1/2 (dilution 1:1,000; cat. no. 4370; Cell Signaling Technology, Inc.) and GAPDH (dilution 1:1,000; cat. no. ab8245; Abcam) overnight at $4^{\circ} \mathrm{C}$. The membranes were subsequently probed with goat anti-rabbit horseradish peroxidase-labeled secondary antibody (dilution 1:10,000; cat. no. ab6721; Abcam) for $1 \mathrm{~h}$ at room temperature. Target proteins were detected with Clarity ${ }^{\mathrm{TM}}$ Western enhanced chemiluminescence substrate (Bio-Rad Laboratories, Inc., Hercules, CA, USA), according to the manufacturer's protocols. The optical density was analyzed by AlphaEaseFC software (version 5.0, ProteinSimple, San Jose, CA, USA). GAPDH was used as the internal control. All experiments were conducted in triplicate.

Statistical analysis. Each experiment was repeated in triplicate. Differences between different groups were evaluated by one-way analysis of variance, followed by Duncan's multiple range post-hoc test using GraphPad prism 6.0 (GraphPad Software, Inc., La Jolla, CA, USA). Difference between two groups were analyzed by a Student's t-test using Microsoft Excel 2017 (Microsoft Corporation, Redmond, WA, USA). Results are presented as means \pm standard deviation and $\mathrm{P}<0.05$ was considered to indicate a statistically significant difference.

\section{Results}

Effects of NP and si-PKC $\zeta$ on the proliferation of COLO205 cells. The results of MTT indicated that NP $\left(1 \times 10^{-6}-1 \times 10^{-8} \mathrm{~mol} / \mathrm{l}\right)$ could significantly induce the proliferation of COLO205 cells $(\mathrm{F}=48.66 ; \mathrm{P}<0.01)$ in a time-and dose-dependent manner, compared with the control group (Fig. 1). Compared with the NC group, the proliferation of COLO205 cells demonstrated was significantly reduced by si-PKC $\zeta$ transfection in a time-dependent manner $(\mathrm{P}<0.01)$; however, recovery of proliferation was indicated following NP treatment (Fig. 1).

Effects of NP and si-PKC $\zeta$ on the cell cycle. Flow cytometry was used to investigate the influence of NP and PKC $\zeta$ on the cell cycle. Compared with the control group, the ratio of G0/G1 phase cells was significantly reduced by NP treatment $\left(\mathrm{t}=9.25,13.17\right.$ and 14.74 for $1 \times 10^{-8}, 1 \times 10^{-7}$ and $1 \times 10^{-6} \mathrm{~mol} / 1 \mathrm{NP}$, 


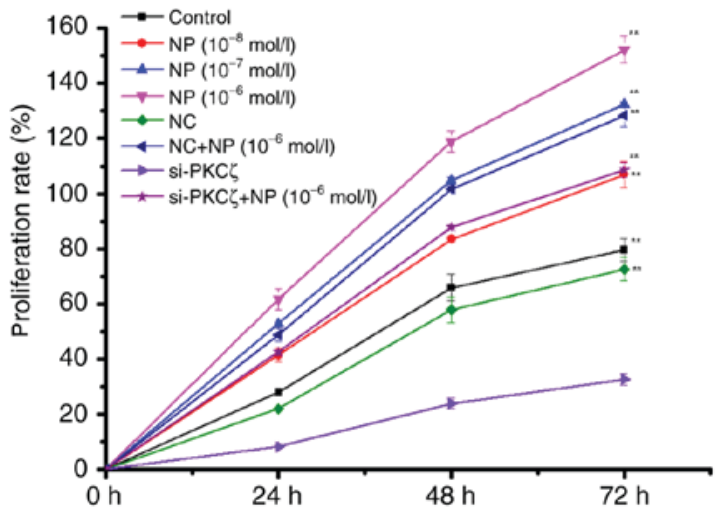

Figure 1. The effect of NP and si-PKC $\zeta$ on the proliferation rate. $\mathrm{COLO} 205$ cells were treated with NP $\left(1 \times 10^{-6}-1 \times 10^{-8} \mathrm{~mol} / \mathrm{l}\right)$, si-PKC $\xi$, si-NC, and si-NC or si-PKC $\zeta$ with NP $\left(10^{-6} \mathrm{~mol} / \mathrm{l}\right)$. NP, nonylphenol; si, small interfering; PKC $\zeta$, protein kinase $\mathrm{C} \xi ; \mathrm{NC}$, siRNA negative control. ${ }^{* *} \mathrm{P}<0.01 \mathrm{vs}$. Control at $72 \mathrm{~h}$. respectively; all $\mathrm{P}<0.01$; Fig. $2 \mathrm{~A}$ ), and significantly increased by the suppression of $\mathrm{PKC} \xi$ expression $(\mathrm{t}=11.29 ; \mathrm{P}<0.01)$, however, this elevation was suppressed by NP treatment $(\mathrm{t}=33.35 ; \mathrm{P}<0.01)$ (Fig. 2B). Furthermore, NP treatment increased the ratio of $\mathrm{S}$ phase cells, compared with the control group $(\mathrm{t}=22.67,37.02$ and 47.41 for $1 \times 10^{-8}, 1 \times 10^{-7}$ and $1 \times 10^{-6} \mathrm{~mol} / 1 \mathrm{NP}$, respectively; all $\mathrm{P}<0.01$; Fig. 2A). Following si-PKC $\zeta$ transfection, the ratio of $\mathrm{S}$ phase cells was significantly decreased compared with the $\mathrm{NC}$ group $(\mathrm{t}=1.83 ; \mathrm{P}<0.05)$, however, it was significantly increased following NP treatment $(\mathrm{t}=51.31 ; \mathrm{P}<0.01)$ (Fig. 2B).

Effects of NP and si-PKC $\zeta$ on cell apoptosis. To evaluate the influence of NP and PKC $\zeta$ on cell apoptosis, flow cytometry was utilized to identify any changes in the apoptotic rate of cells following NP treatment or si-PKC $\zeta$ transfection. The results indicated that the ratio of viable to non-viable apoptotic
A

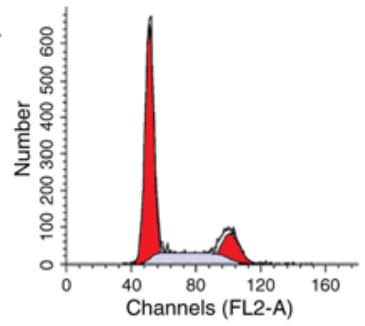

Control

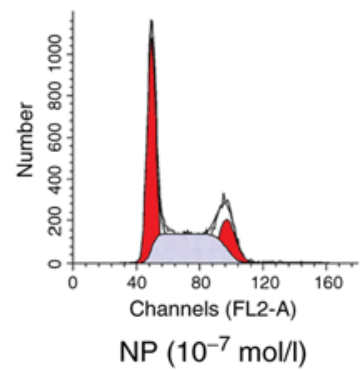

B

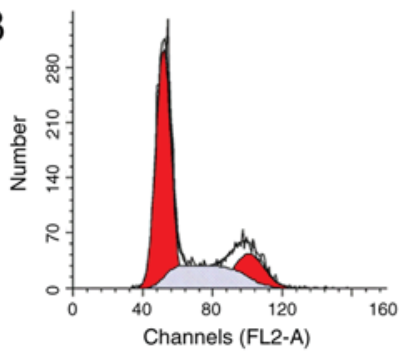

NC

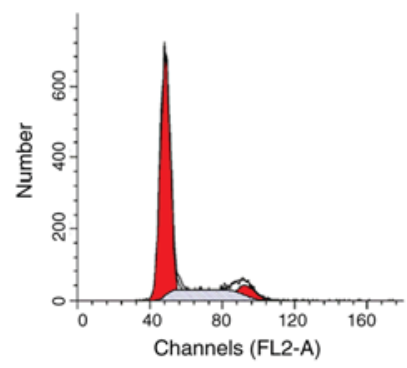

si-PKCל
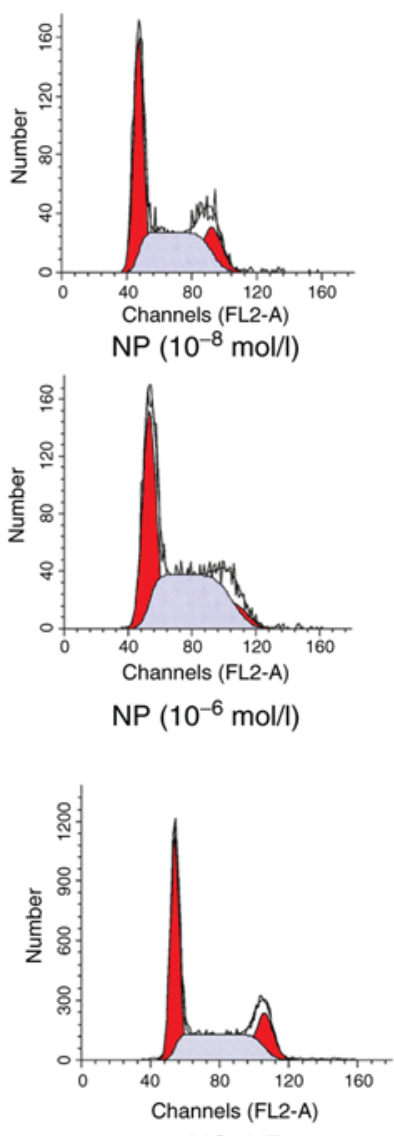

$\mathrm{NC}+\mathrm{NP}$

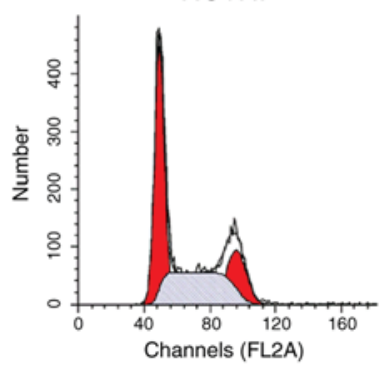

si-PKC +

$\mathrm{NP}\left(10^{-6} \mathrm{~mol} / \mathrm{l}\right)$
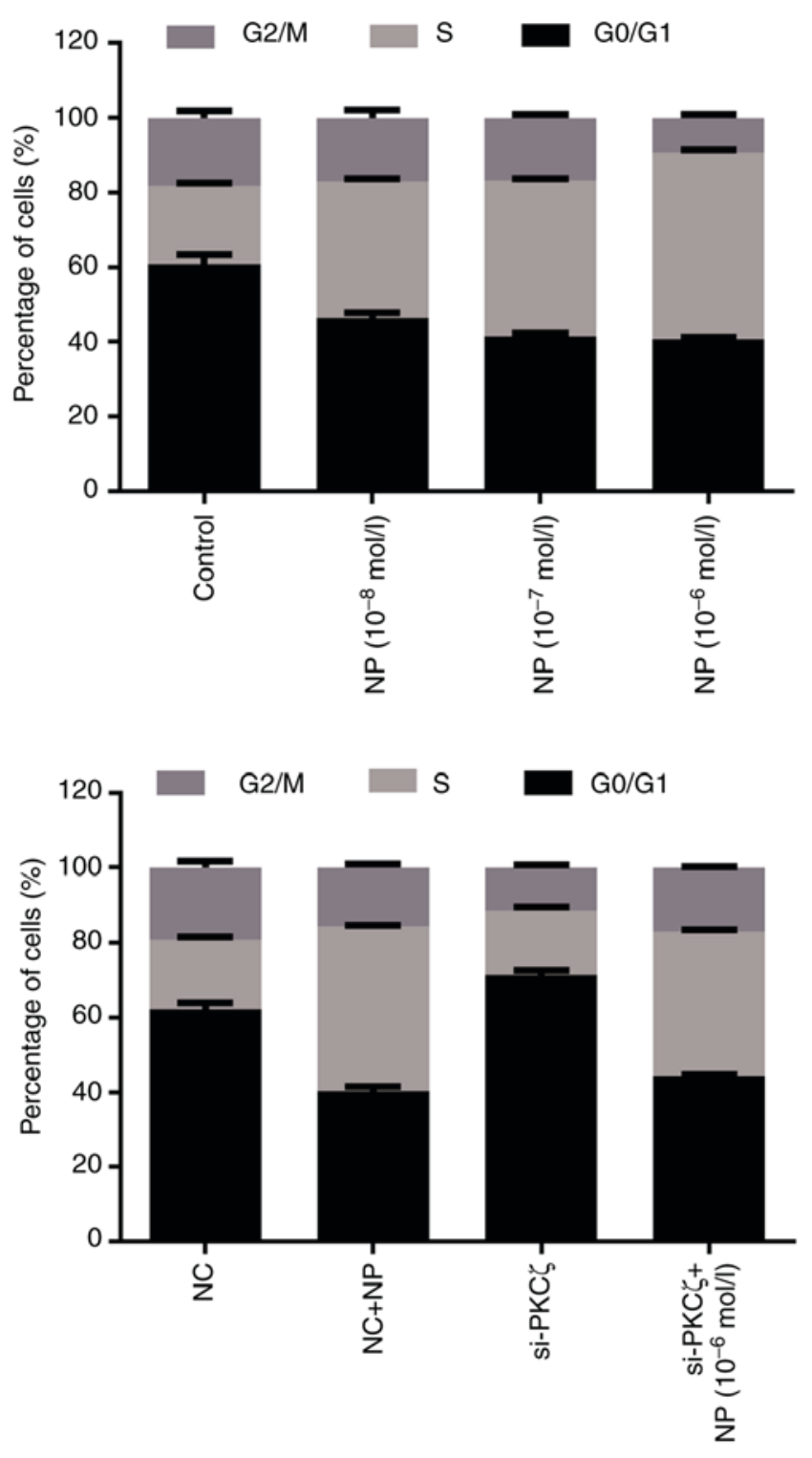

Figure 2. The effect of NP and si-PKC $\zeta$ on the cell cycle. COLO205 cells were treated with the following: $\mathrm{NP}\left(0,1 \times 10^{-6}, 1 \times 10^{-7}\right.$ or $\left.1 \times 10^{-8} \mathrm{~mol} / 1\right)$, si-PKC $\zeta$, si-NC, and si-PKC $\zeta$ or si-NC and NP $\left(10^{-6} \mathrm{~mol} / \mathrm{l}\right)$. (A) The effect of NP on the cell cycle. (B) The effect of NP and si-PKC $\zeta$ on the cell cycle. PKC $\zeta$, protein kinase $\mathrm{C} \xi$; NC, siRNA negative control; NP, nonylphenol; si, small interfering. 

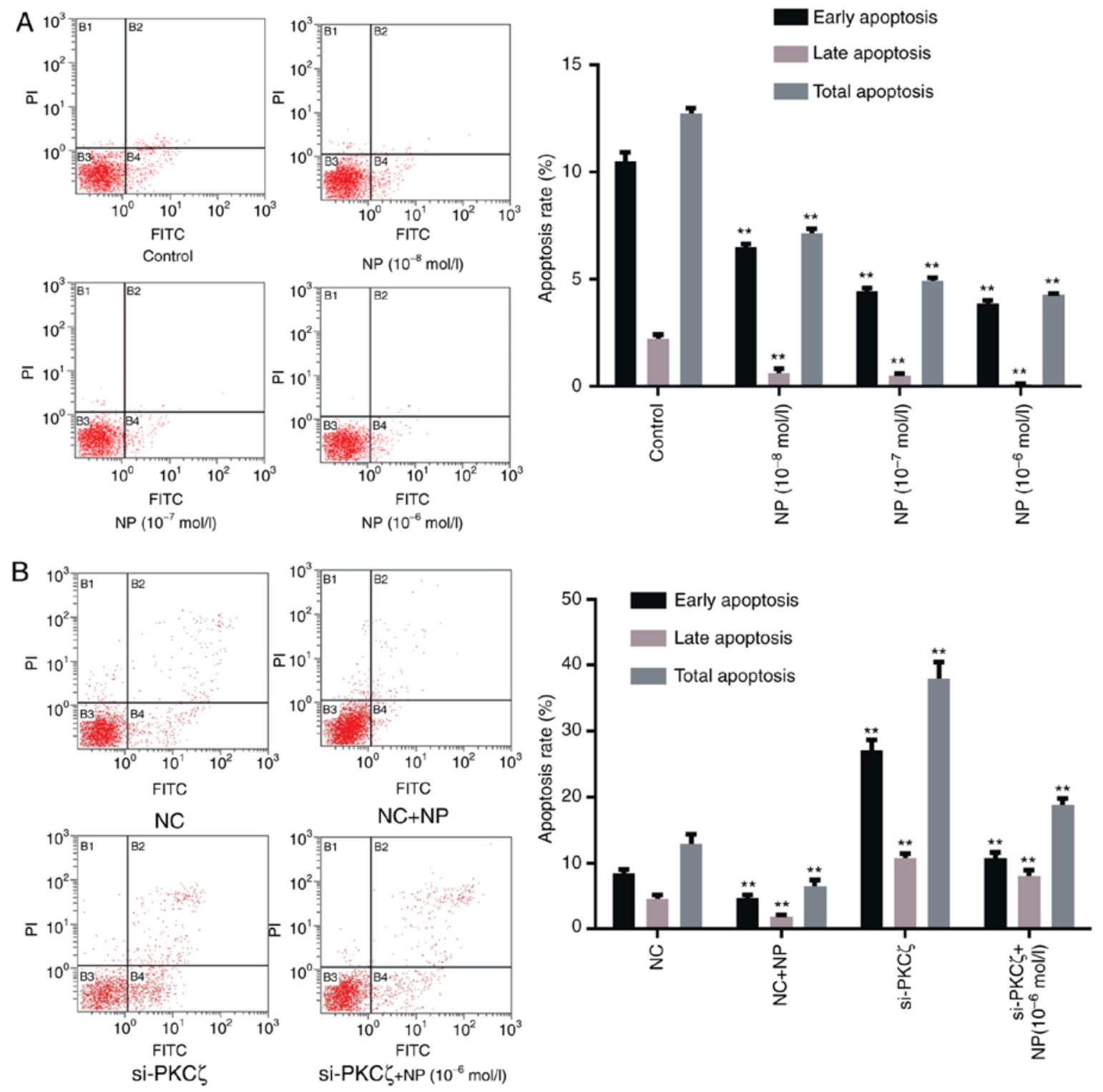

Figure 3. The effect of NP and si-PKC $\zeta$ on the apoptotic rate of COLO205 cells. (A) The effect of NP on the apoptotic rate of COLO205 cells. ${ }^{* *} \mathrm{P}<0.01$ vs. control group. (B) The effect of NP and si-PKC $\zeta$ on the apoptotic rate of COLO205 cells. ${ }^{* *} \mathrm{P}<0.01$ vs. NC group. PKC $\zeta$, protein kinase $\mathrm{C} \xi$; si, small interfering; NC, siRNA negative control; NP, nonylphenol; PI, propidium iodide; FITC, fluorescein isothiocyanate.

cells in the NP treatment group was lower than that in the control group $(\mathrm{P}<0.01$; Fig. 3A). Suppression of PKC $\zeta$ expression significantly increased the ratio of viable apoptotic and non-viable apoptotic cells ( $\mathrm{P}<0.01$ vs. NC group), however, the ratio of apoptotic cells decreased following NP treatment (Fig. 3B).

Expression change of cell cycle-associated proteins. Compared to the control group, NP treatment significantly upregulated the expression of cyclin D1 and cyclin E, and downregulated the expression of $\mathrm{p} 27$ (all $\mathrm{P}<0.05$; Fig. 4A). Following siRNA transfection, the expression of cyclin D1 and cyclin E was significantly reduced by $\mathrm{PKC} \zeta$ suppression, and the expression of p27 was increased (all $\mathrm{P}<0.01$ vs. NC group). Following NP treatment in the si-PKC $\zeta$-transfected cells, the expression of cyclin D1 and E increased, whereas the expression of p27 decreased (Fig. 4B).
Expression change of apoptosis-associated protein. Additionally, the expression of apoptosis-associated proteins Bcl-2 and Bad was examined (Fig. 5A). The results of the western blot analysis indicated that NP treatment had no significant effect on the expression of Bcl-2, but significantly reduced the expression of $\mathrm{Bad}(\mathrm{P}<0.01$ for all concentrations of NP vs. control). The expression of Bad was significantly increased following si-PKC $\zeta$ transfection $(\mathrm{P}<0.01$ vs. NC group) and significantly reduced by subsequent NP treatment $(\mathrm{P}<0.01$ vs. si-PKC' $\zeta$ group) (Fig. 5B).

Expression change of $P K C \zeta$ and ERK1/2. The results of the western blot analysis indicated that the expression of $\mathrm{PKC}_{\zeta}$ and the phosphorylation of ERK1/2 were significantly increased by NP $\left(\mathrm{P}<0.05\right.$ for $1 \times 10^{-8} ; \mathrm{P}<0.01$ for $1 \times 10^{-7}-1 \times 10^{-6}$; Fig. $\left.6 \mathrm{~A}\right)$. Following si-PKC $\zeta$ transfection, the expression of $\mathrm{PKC} \zeta$ and the phosphorylation of ERK1/2 were significantly reduced 
A
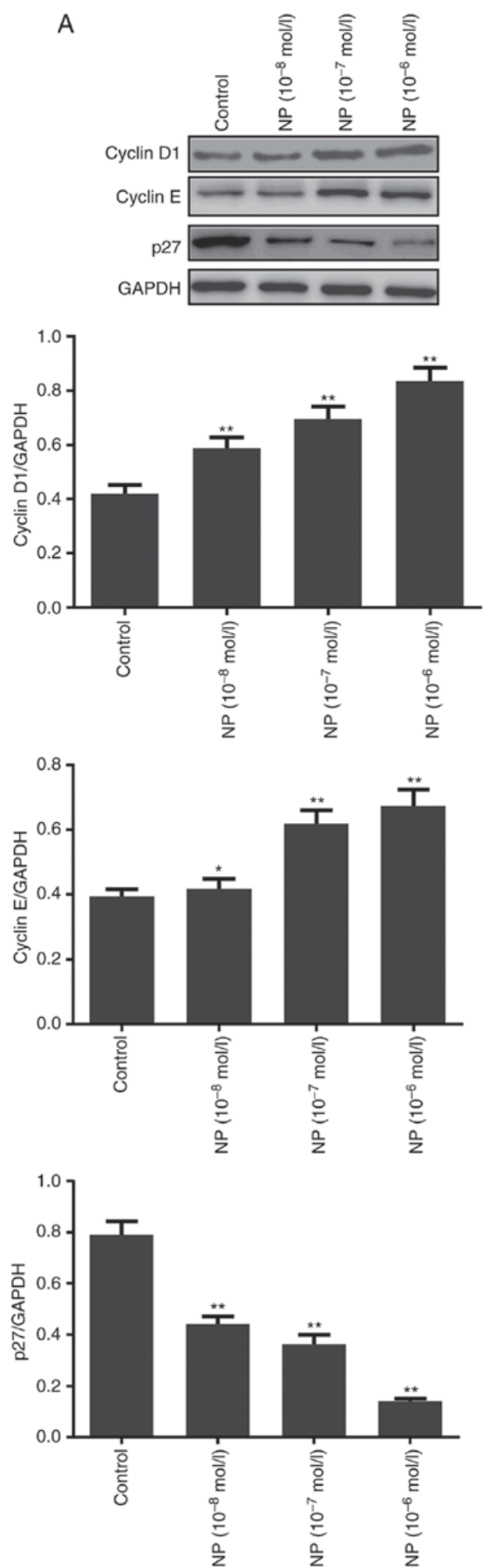

B
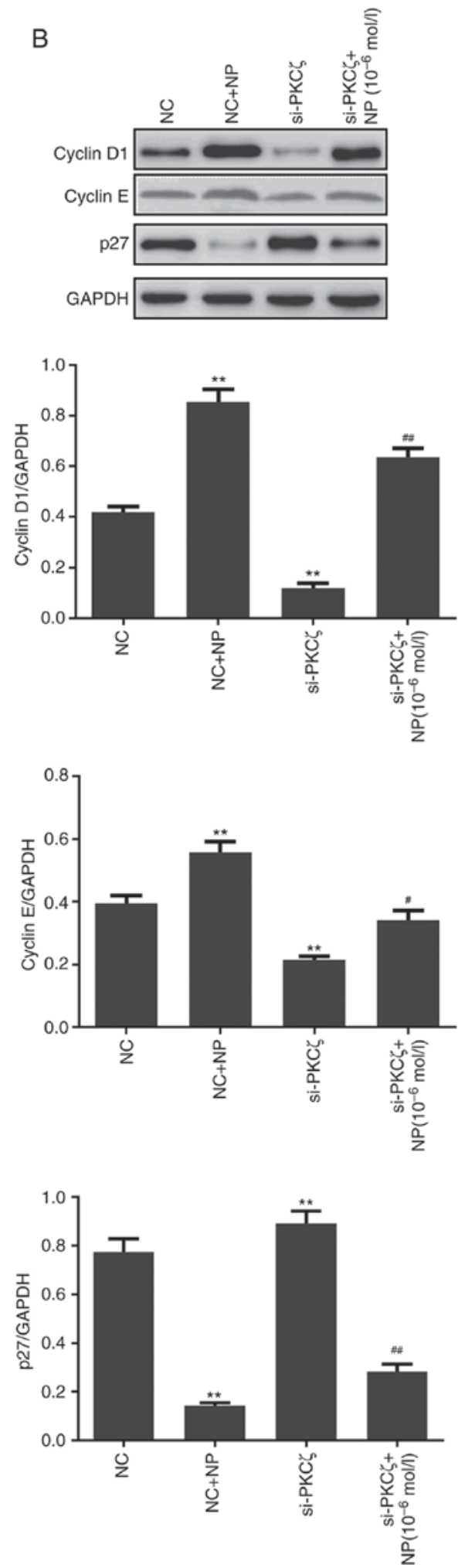

Figure 4. The effect of NP and si-PKC $\zeta$ on the expression of cell cycle-associated proteins. (A) The effect of NP on the expression of cyclin D1, cyclin E and p27. ${ }^{*} \mathrm{P}<0.05$ and ${ }^{* *} \mathrm{P}<0.01$ vs. control group. (B) The effect of NP and si-PKC $\zeta$ on the expression of cyclin $\mathrm{D} 1$, cyclin $\mathrm{E}$ and $\mathrm{p} 27 .{ }^{* *} \mathrm{P}<0.01$ vs. NC group; ${ }^{*} \mathrm{P}<0.05$ and ${ }^{\# \#} \mathrm{P}<0.01$ vs. si-PKC $\zeta$. PKC $\zeta$, protein kinase $\mathrm{C} \xi$; si, small interfering; NC, siRNA negative control; NP, nonylphenol; p27, cyclin-dependent kinase inhibitor.

(both $\mathrm{P}<0.01$ vs. NC), however, this was significantly recovered following NP treatment (both $\mathrm{P}<0.01$ vs. siPKC $\zeta$ alone) (Fig. 6B). The phosphorylation of PKC $\zeta$ was also influenced by NP treatment. Following NP treatment, the phosphorylation of PKC $\zeta$ was significantly increased for all concentrations of
$\mathrm{NP}$, compared with the control $(\mathrm{P}<0.01 ; \mathrm{P}<0.05 ;$ Fig. $7 \mathrm{~A})$. The phosphorylation level of $\mathrm{PKC} \zeta$ did not change significantly following si-PKC $\zeta$ transfection, however, subsequent NP treatment significantly increased the phosphorylation $(\mathrm{P}<0.01$ vs. si-PKC $\zeta$ alone; Fig. 7B). 
A
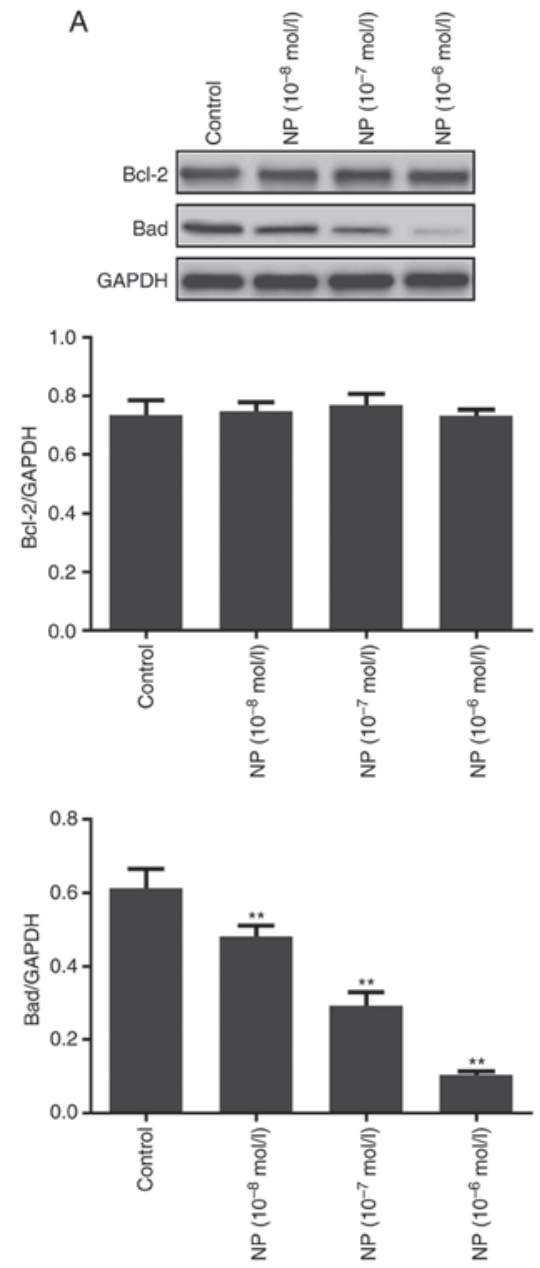

B
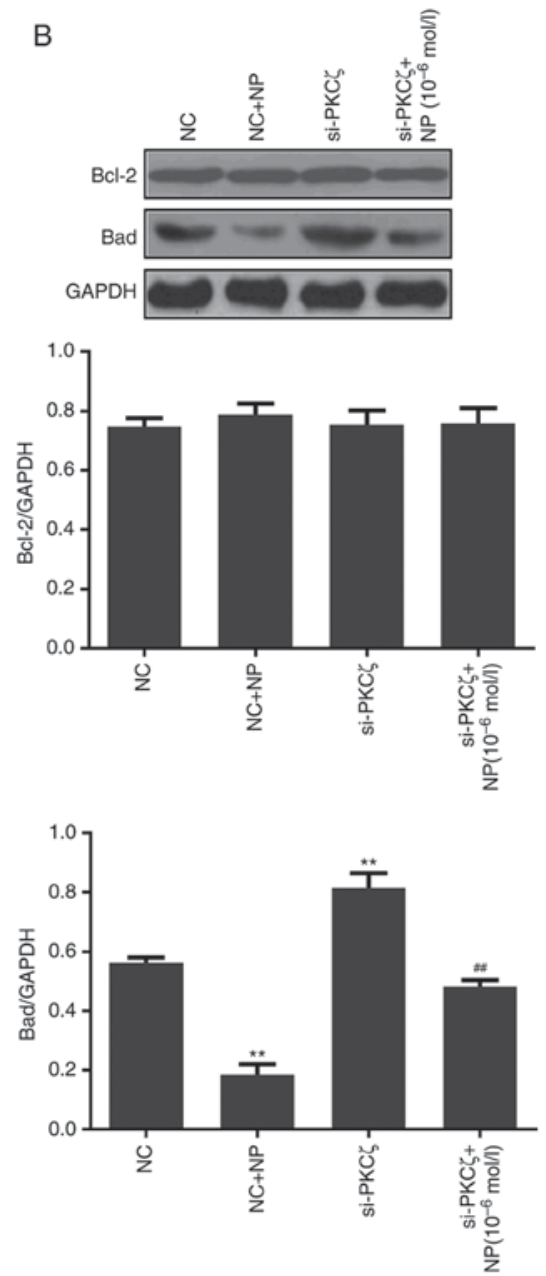

Figure 5. The effect of NP and si-PKC $\zeta$ on the expression of apoptosis-associated proteins. (A) The effect of NP on the expression of Bcl-2 and Bad ${ }^{* *} \mathrm{P}<0.01$ vs. control group. (B) The effect of NP and si-PKC $\zeta$ on the expression of $\mathrm{Bcl}-2$ and $\mathrm{Bad}{ }^{* *} \mathrm{P}<0.01$ vs. NC group; and ${ }^{\# \#} \mathrm{P}<0.01$ vs. si-PKC $\zeta$. Bcl-2, B-cell lymphoma-2; Bad, Bcl-2 associated agonist of cell death; $\mathrm{PKC} \zeta$, protein kinase $\mathrm{C} \zeta$; si, small interfering; NC, siRNA negative control; NP, nonylphenol.

\section{Discussion}

Globally, CRC is the third leading cause of cancer-associated morbidity and is the fourth leading cause of cancer-associated mortality (2014) (1). In China, the incidence of CRCs presents an annual rising trend (1), bearing a serious threat to human health. The risk of human CRC is associated with environment, dietary and genetics factors (19). A previous study indicated that $\mathrm{CRC}$ was an estrogen-dependent tumor type, and the level of estrogen in patients was directly associated with the development and prognosis of CRC (2). NP is an EDC, which has the ability to induce endocrine disruption, reproduction disorders and the development of various types of cancer (20-23).

In the present study, NP was indicated to significantly induce the proliferation of COLO205 cells by promoting cells from the G1 phase into the S phase. Cyclin D1 and E are two proteins that have been demonstrated to induce cells transforming from the G1 phase to the S phase, and p21 and p27 are two kinases, which have been reported to inhibit the cell cycle transformation (24-26). In the present study, it was indicated that NP could upregulate the expression of cyclin D1 and $\mathrm{E}$, and downregulate the expression of $\mathrm{p} 27$.
Abnormalities in the cell apoptosis mechanism can induce cell proliferation, which may result in the development of tumors (27). Bcl-2 is an important anti-apoptosis protein, which is considered as an oncogene. Bad is a type of pro-apoptosis protein, which binds to $\mathrm{Bcl}-2$ to prevent apoptosis (28). The dynamic balance of these aforementioned proteins serve an important role in maintaining a normal function of cells. The present study indicated that NP slightly affected the expression of Bcl-2, however, NP could significantly reduce the expression of Bad. Therefore, NP may inhibit apoptosis by inhibiting the pro-apoptotic function of Bad.

PKC $\zeta$ is involved in the proliferation and transfer of various tumor cells (13-15). Inhibiting the expression of PKC $\zeta$ has been reported to suppress the invasion ability of CRC, breast cancer and glioma (16). A previous study indicated that PKC $\zeta$ promotes tumor cell proliferation and the regulation of apoptosis by phosphorylation of STAT3 (29). The results of the present study indicated that NP could induce the expression of $\mathrm{PKC} \zeta$, in addition to the phosphorylation of ERK1/2. However, suppression of PKC $\zeta$ significantly reduced the phosphorylation of ERK1/2. The aforementioned results indicated that NP may induce the proliferation of CRC cells by upregulating the expression of $\mathrm{PKC} \zeta$ and increasing the phosphorylation of 
A
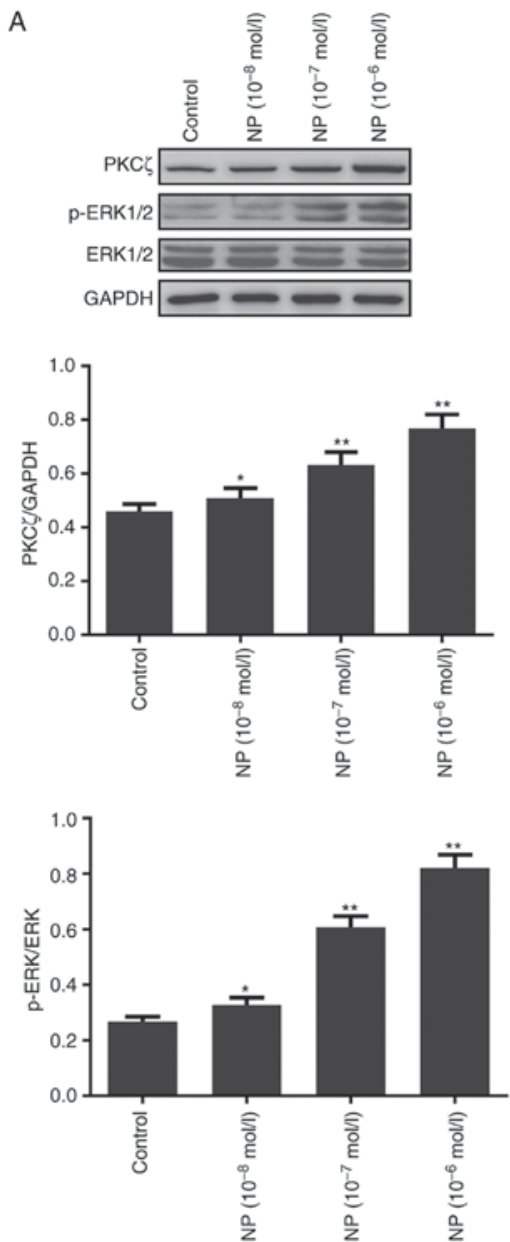

B
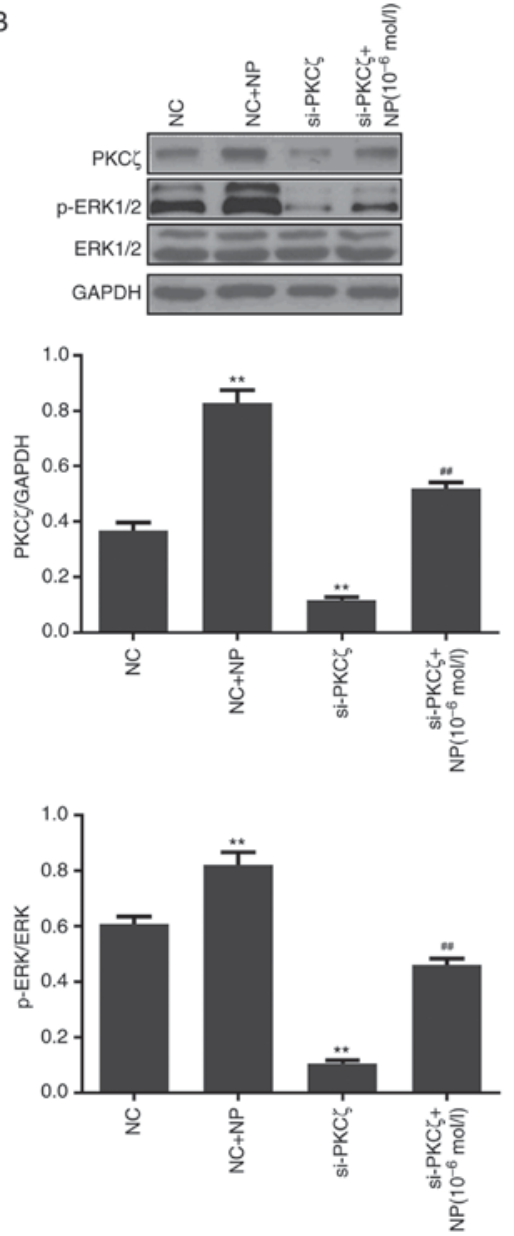

Figure 6. The effect of NP and si-PKC $\zeta$ on the expression of PKC $\zeta$ and ERK1/2. (A) The effect of NP on the expression of PKC $\zeta$ and p-ERK/ERK1/2. "P<0.05 and ${ }^{* *} \mathrm{P}<0.01$ vs. control group. (B) The effect of NP and si-PKC $\zeta$ on the expression of $\mathrm{PKC} \zeta$ and $\mathrm{p}-\mathrm{ERK} / \mathrm{ERK} 1 / 2 .{ }^{* *} \mathrm{P}<0.01$ vs. NC group; and ${ }^{\# \#} \mathrm{P}<0.01$ vs. si-PKC $\zeta$. p, phosphorylated; PKC $\zeta$, protein kinase $\mathrm{C} \zeta$; si, small interfering; NC, siRNA negative control; NP, nonylphenol; ERK, extracellular-signal-regulated kinase.

A

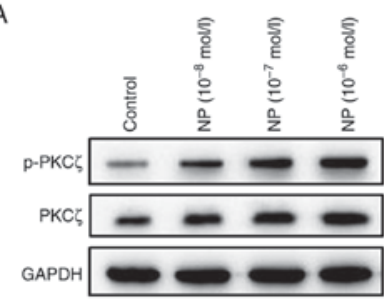

B

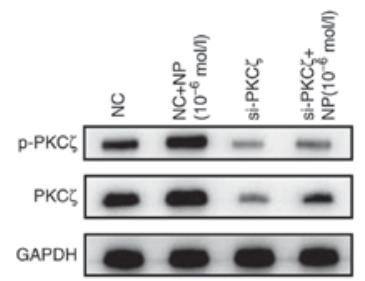

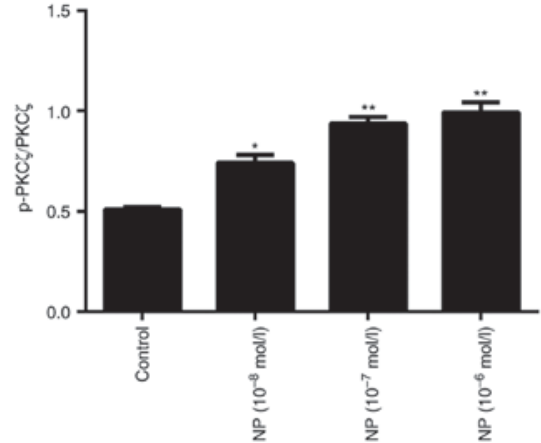

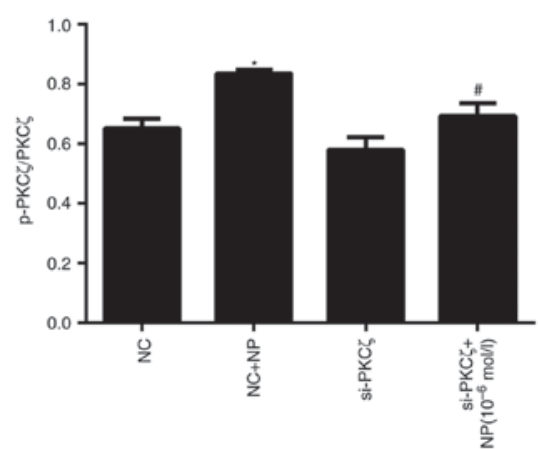

Figure 7. The effect of NP and si-PKC $\zeta$ on the phosphorylation of PKC $\zeta$. (A) The effect of NP on the phosphorylation of PKC $\zeta$. "P $<0.05$ and ${ }^{* *} \mathrm{P}<0.01$ vs. control group. (B) The effect of NP and si-PKC $\zeta$ on the phosphorylation of PKC $\zeta$. "P $<0.05$ vs. NC group; and ${ }^{~} \mathrm{P}<0.05$ vs. si-PKC $\zeta$ group. p, phosphorylated; $\mathrm{PKC} \zeta$, protein kinase $\mathrm{C} \zeta$; si, small interfering; NC, siRNA negative control; NP, nonylphenol. 
ERK1/2. Further investigation is required in order to examine the underlying mechanism of PKC $\zeta$ overexpression by NP.

In conclusion, the present study identified the effect of NP on the expression and activity of PKC $\zeta$ using RNAi technology. The results indicated that NP could induce the proliferation of COLO205 cells by activating the ERK pathway through PKC $\zeta$ activation. The present study provides new direction for CRC prevention and therapy. However, the underlying mechanisms of NP on the development of CRCs requires further study.

\section{Acknowledgements}

Not applicable.

\section{Funding}

The present study was supported by the Natural Scientific Foundation in the Science and Technology Department of Guizhou Province, China (grant no. J20142185).

\section{Availability of data and materials}

The datasets used and/or analyzed during the current study are available from the corresponding author on reasonable request.

\section{Authors' contributions}

HH and MW cultured the COLO205 cells, and performed the NP treatment and siRNA transfection. JX examined the proliferation, cell cycle and apoptosis of the COLO205 cells. MX and XZ designed the experiment. XY performed the western blot analysis and was a major contributor in writing the manuscript. All authors read and approved the final manuscript.

\section{Ethics approval and consent to participate}

Not applicable.

\section{Patient consent for publication}

Not applicable.

\section{Competing interests}

The authors declare no competing financial interests.

\section{References}

1. Chen W, Zheng R, Baade PD, Zhang S, Zeng H, Bray F, Jemal A, Yu XQ and He J: Cancer statistics in China, 2015. CA Cancer J Clin 66: 115-132, 2016.

2. Fogel EL, Shahda S, Sandrasegaran K, DeWitt J, Easler JJ, Agarwal DM, Eagleson M, Zyromski NJ, House MG, Ellsworth S, et al: A multidisciplinary approach to pancreas cancer in 2016: A review. Am J Gastroenterol 112: 537-554, 2017.

3. Stedman KE, Moore GE and Morgan RT: Estrogen receptor proteins in diverse human tumors. Arch Surg 115: 244-248, 1980.

4. Hwang KA, Park SH, Yi BR and Choi KC: Gene alterations of ovarian cancer cells expressing estrogen receptors by estrogen and bisphenol a using microarray analysis. Lab Anim Res 27: 99-107, 2011.
5. Jeung EB and Choi KC: Toxicological mechanism of endocrine disrupting chemicals: Is estrogen receptor involved? Toxicol Res 26: 237-243, 2010.

6. Park MA, Hwang KA and Choi KC: Diverse animal models to examine potential role(s) and mechanism of endocrine disrupting chemicals on the tumor progression and prevention: Do they have tumorigenic or anti-tumorigenic property? Lab Anim Res 27: 265-273, 2011

7. Schug TT, Janesick A, Blumberg B and Heindel JJ: Endocrine disrupting chemicals and disease susceptibility. J Steroid Biochem Mol Biol 127: 204-215, 2011.

8. Roy JR, Chakraborty S and Chakraborty TR: Estrogen-like endocrine disrupting chemicals affecting puberty in humans-a review. Med Sci Monit 15: RA137-RA145, 2009.

9. Kang NH, Hwang KA, Kim TH, Hyun SH, Jeung EB and Choi KC: Induced growth of BG-1 ovarian cancer cells by $17 \beta$-estradiol or various endocrine disrupting chemicals was reversed by resveratrol via downregulation of cell cycle progression. Mol Med Rep 6: 151-156, 2012.

10. Kim SH, Nam KH, Hwang KA and Choi KC: Influence of hexabromocyclododecane and 4-nonylphenol on the regulation of cell growth, apoptosis and migration in prostatic cancer cells. Toxicol In Vitro 32: 240-247, 2016.

11. Yang X, Huang H, Wang M, Zheng X, Xu J and Xie M: Effect of nonylphenol on the regulation of cell growth in colorectal cancer cells. Mol Med Rep 16: 2211-2216, 2017.

12. Mellor H and Parker PJ: The extended protein kinase $\mathrm{C}$ superfamily. Biochem J 332: 281-292, 1998.

13. Yao S, Bee A, Brewer D, Dodson A, Beesley C, Ke Y, Ambroisine L, Fisher G, Møller H, Dickinson T, et al: PRKC- $\zeta$ expression promotes the aggressive phenotype of human prostate cancer cells and is a novel target for therapeutic intervention. Genes Cancer 1: 444-464, 2010.

14. Guo H, Gu F, Li W, Zhang B, Niu R, Fu L, Zhang N and Ma Y: Reduction of protein kinase $\mathrm{C}$ zeta inhibits migration and invasion of human glioblastoma cells. J Neurochem 109: 203-213, 2009.

15. Huang S, Ouyang N, Lin L, Chen L, Wu W, Su F, Yao Y and Yao H: HGF-induced PKC $\zeta$ activation increases functional CXCR4 expression in human breast cancer cells. PLoS One 7: e29124, 2012.

16. Luna-Ulloa LB, Hernández-Maqueda JG, Santoyo-Ramos P, Castañeda-Patlán MC and Robles-Flores M: Protein kinase $\mathrm{C} \xi$ is a positive modulator of canonical Wnt signaling pathway in tumoral colon cell lines. Carcinogenesis 32: 1615-1624, 2011.

17. Kim YS, Hwang KA, Hyun SH, Nam KH, Lee CK and Choi KC: Bisphenol A and nonylphenol have the potential to stimulate the migration of ovarian cancer cells by inducing epithelial-mesenchymal transition via an estrogen receptor dependent pathway. Chem Res Toxicol 28: 662-671, 2015.

18. Park MA and Choi KC: Effects of 4-nonylphenol and bisphenol A on stimulation of cell growth via disruption of the transforming growth factor- $\beta$ signaling pathway in ovarian cancer models. Chem Res Toxicol 27: 119-128, 2014.

19. Tang L, Shen H, Li X, Li Z, Liu Z, Xu J, Ma S, Zhao X, Bai X, Li M, et al: MiR-125a-5p decreases after long non-coding RNA HOTAIR knockdown to promote cancer cell apoptosis by releasing caspase 2. Cell Death Dis 7: e2137, 2016.

20. Bonefeld-Jørgensen EC, Long M, Hofmeister MV and Vinggaard AM: Endocrine-disrupting potential of bisphenol A, bisphenol A dimethacrylate, 4-n-nonylphenol and 4-n-octylphenol in vitro: New data and a brief review. Environ Health Perspect 115 (Suppl 1): S69-S76, 2007.

21. In SJ, Kim SH, Go RE, Hwang KA and Choi KC: Benzophenone-1 and nonylphenol stimulated MCF-7 breast cancer growth by regulating cell cycle and metastasis-related genes via an estrogen receptor alpha-dependent pathway. J Toxicol Environ Health A 78: 492-505, 2015.

22. Kim SH, Hwang KA, Shim SM and Choi KC: Growth and migration of LNCaP prostate cancer cells are promoted by triclosan and benzophenone-1 via an androgen receptor signaling pathway. Environ Toxicol Pharmacol 39: 568-576, 2015.

23. Liu C, Sun Y, Song Y, Saito T and Kurasaki M: Nonylphenol diethoxylate inhibits apoptosis induced in PC12 cells. Environ Toxicol 31: 1389-1398, 2016.

24. Stamatakos M, Palla V, Karaiskos I, Xiromeritis K, Alexiou I, Pateras I and Kontzoglou K: Cell cyclins: Triggering elements of cancer or not? World J Surg Oncol 8: 111, 2010.

25. Roy A and Banerjee S: p27 and leukemia: Cell cycle and beyond. J Cell Physiol 230: 504-509, 2015. 
26. Sandhu C and Slingerland J: Deregulation of the cell cycle in cancer. Cancer Detect Prev 24: 107-118, 2000.

27. Majno $\mathrm{G}$ and Joris I: Apoptosis, oncosis, and necrosis. An overview of cell death. Am J Pathol 146: 3-15, 1995.

28. Hassan M, Watari H, AbuAlmaaty A, Ohba Y and Sakuragi N: Apoptosis and molecular targeting therapy in cancer. Biomed Res Int 2014: 150845, 2014.
29. Butler AM, Scotti Buzhardt ML, Li S, Smith KE, Fields AP and Murray NR: Protein kinase $\mathrm{C}$ zeta regulates human pancreatic cancer cell transformed growth and invasion through a STAT3-dependent mechanism. PLoS One 8: e72061, 2013. 